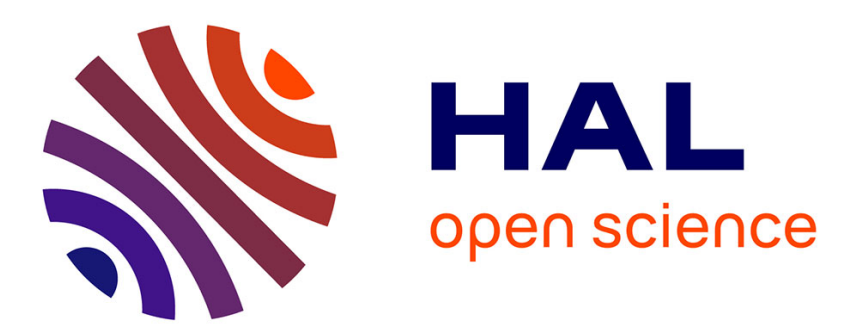

\title{
Survival of Plant Seeds, Their UV Screens, and nptII DNAfor 18 Months Outside the International Space Station
}

David Tepfer, Andreja Zalar, Sydney Leach

\section{- To cite this version:}

David Tepfer, Andreja Zalar, Sydney Leach. Survival of Plant Seeds, Their UV Screens, and nptII DNAfor 18 Months Outside the International Space Station. Astrobiology, 2012, 12 (5), pp.517-528. 10.1089/ast.2011.0744 . hal-02644860

\section{HAL Id: hal-02644860 \\ https: / hal.inrae.fr/hal-02644860}

Submitted on 28 May 2020

HAL is a multi-disciplinary open access archive for the deposit and dissemination of scientific research documents, whether they are published or not. The documents may come from teaching and research institutions in France or abroad, or from public or private research centers.
L'archive ouverte pluridisciplinaire HAL, est destinée au dépôt et à la diffusion de documents scientifiques de niveau recherche, publiés ou non, émanant des établissements d'enseignement et de recherche français ou étrangers, des laboratoires publics ou privés. 


\title{
Survival of Plant Seeds, Their UV Screens, and nptII DNA for 18 Months Outside the International Space Station
}

\author{
David Tepfer, ${ }^{1}$ Andreja Zalar, ${ }^{2}$ and Sydney Leach ${ }^{3}$
}

\begin{abstract}
The plausibility that life was imported to Earth from elsewhere can be tested by subjecting life-forms to space travel. Ultraviolet light is the major liability in short-term exposures (Horneck et al., 2001), and plant seeds, tardigrades, and lichens-but not microorganisms and their spores-are candidates for long-term survival (Anikeeva et al., 1990; Sancho et al., 2007; Jönsson et al., 2008; de la Torre et al., 2010).

In the present study, plant seeds germinated after 1.5 years of exposure to solar UV, solar and galactic cosmic radiation, temperature fluctuations, and space vacuum outside the International Space Station. Of the 2100 exposed wild-type Arabidopsis thaliana and Nicotiana tabacum (tobacco) seeds, 23\% produced viable plants after return to Earth. Survival was lower in the Arabidopsis Wassilewskija ecotype and in mutants (tt4-8 and fah1-2) lacking UV screens. The highest survival occurred in tobacco (44\%). Germination was delayed in seeds shielded from solar light, yet full survival was attained, which indicates that longer space travel would be possible for seeds embedded in an opaque matrix. We conclude that a naked, seed-like entity could have survived exposure to solar UV radiation during a hypothetical transfer from Mars to Earth.

Chemical samples of seed flavonoid UV screens were degraded by UV, but their overall capacity to absorb UV was retained. Naked DNA encoding the nptII gene (kanamycin resistance) was also degraded by UV. A fragment, however, was detected by the polymerase chain reaction, and the gene survived in space when protected from UV. Even if seeds do not survive, components (e.g., their DNA) might survive transfer over cosmic distances. Key Words: Origin of life-Panspermia—Plant seeds-Flavonoid UV screens-DNA degradationUV resistance-International Space Station. Astrobiology 12, 517-528.
\end{abstract}

\section{Introduction}

$\mathbf{T}$ HE QUESTION OF the origin of life has arisen in diverse human cultures. We know now that sequence-based phylogenetic trees are rooted in microbial ancestors, that microbes appeared within the first billion years of Earth's existence (Westall, 2009), and that all organisms, so far examined, use essentially the same genetic code, suggesting a unique origin for life on Earth. These facts are compatible with, but do not prove, an extraterrestrial origin for the life we know.

Habitable zone planets and the basic molecules of life, including water, are found within and beyond our solar system (Barman, 2007; Eisner, 2007). Could life be dispersed among these potential exohabitats? The ability of life-forms to withstand space travel can be used as a measure of the plausibility of this hypothesis. In the SEEDS portion of the EXPOSE-E project, we thus exposed Arabidopsis and to- bacco seeds to space conditions for 18 months outside the International Space Station (ISS), orbiting at $440 \mathrm{~km}$ altitude (Rabbow et al., 2009) (Fig. 1). Five wild-type and mutant seed genotypes were tested, with each genotype repeated at three dispersed positions (Fig. 2). Behind this fully exposed layer (S1), identical samples (S2) were protected from UV light but exposed to space vacuum, temperatures, and galactic cosmic radiation. In a ground simulation, another set of samples (G1) in an identical sample carrier was subjected to simulated space vacuum, temperature, and $U_{2} 200-400 \mathrm{~nm}$ light, in accordance with data from sensors on EXPOSE, with a dark layer (G2) that lacked UV exposure. Lab controls (L0) were stored at $4^{\circ} \mathrm{C}$.

Arabidopsis thaliana was chosen for its small seeds (permitting large sample sizes) and the availability of mutants and information about the composition of the seed coat. Two wild-type Arabidopsis ecotypes, Wassilewskija (Ws-2) and

\footnotetext{
${ }^{1}$ Institut National de la Recherche Agronomique, Versailles, France.

${ }^{2}$ Université de Versailles Saint-Quentin-en-Yvelines, Versailles, France.

${ }^{3}$ LERMA, Observatoire de Paris-Meudon, Meudon, France.
} 


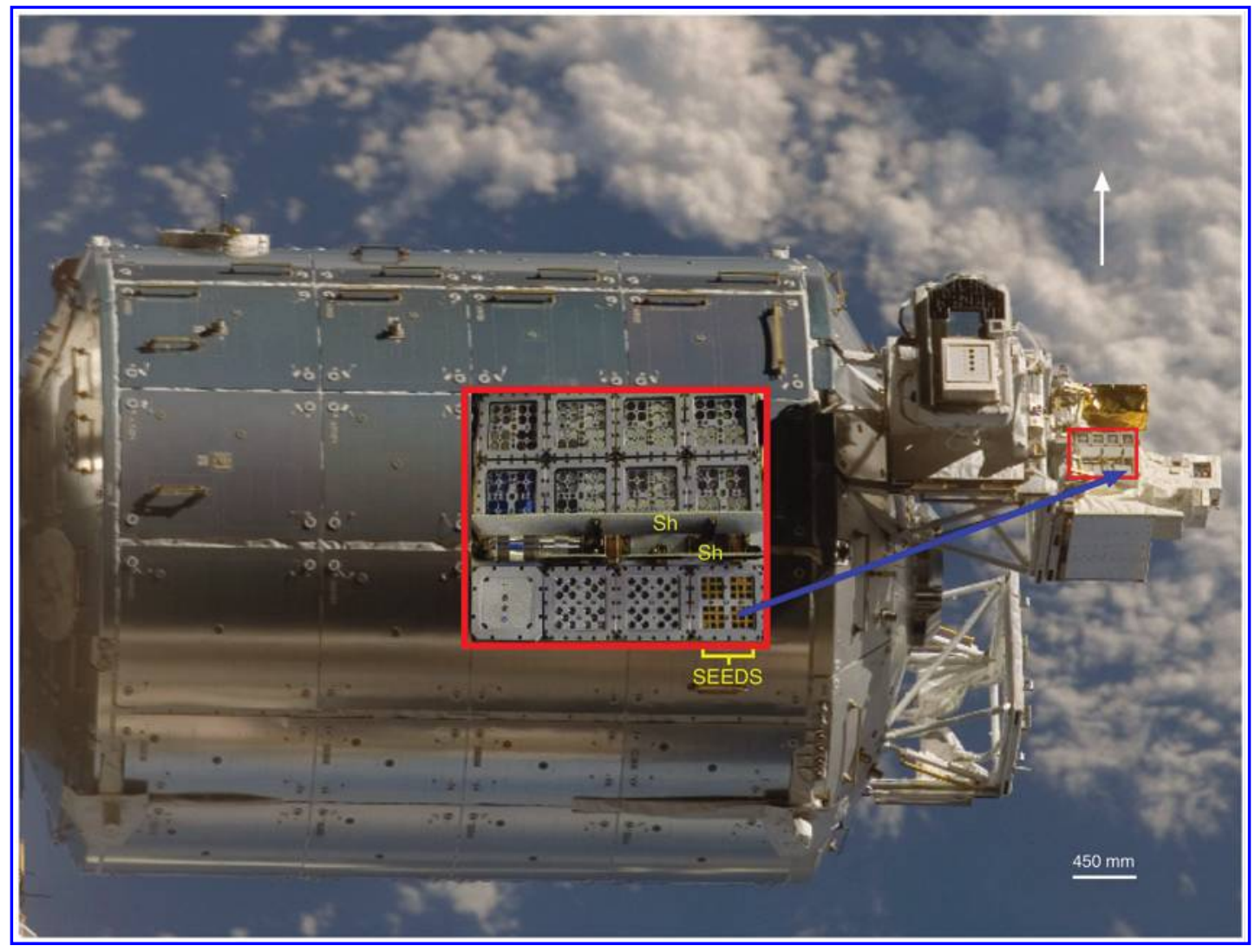

FIG. 1. EXPOSE and SEEDS on the Columbus module of the ISS (Photo courtesy of NASA). EXPOSE (small red box) is on the EuTEF platform. SEEDS is covered by a protective shutter (closed in this photo, taken prior to the start of exposure). Columbus, the European module, is to the left of EXPOSE. Proximal sources of UV and solar wind shadows include Columbus, the other experiments surrounding EXPOSE on the EuTEF platform, and the protective shutter, which was perpendicular to the surface of SEEDS during exposure but closed during transport. Insert (large red box), position of SEEDS on EXPOSE, with the shutters (Sh) open, in the same orientation as in Fig 3, with seeds on the lower right. White arrow, direction of flight, except during shuttle docking, when it was inverted $180^{\circ}$. The external dimensions of EXPOSE were $440 \times 380 \times 250 \mathrm{~mm}$. Color images available online at www.liebertonline.com/ast

Columbia (Col-0), were exposed, with a mutant lacking a UV screen for each ecotype. Flavonoids and sinapate esters protect plants from UV light (Li et al., 1993; Stapleton and Walbot, 1994; Landry et al., 1995; Sheahan, 1996), and flavonoids are also antioxidants (Pietta, 2000; Urquiaga and Leighton, 2000; Williams et al., 2004). The tt4-8 mutant (Debeaujon et al., 2003) lacked flavonoids due to a T-DNA insertion into the chalcone synthase gene, and the fah1-2 mutant (Columbia background) lacked sinapate esters due to a dysfunctional ferulate-5-hydroxylase (Chapple et al., 1992; Sheahan, 1996). Tobacco (Nicotiana tabacum) was chosen for its developed endosperm and redundant genome, in contrast to the vestigial endosperm and the compact genome of Arabidopsis. In addition to the Havana tobacco wild type, a derivative (PT) was tested, carrying a marker in the chloroplast DNA that did not effect phenotype (Carrer et al., 1993).

Flavonoids and DNA were exposed as dry films on the inner surfaces of $\mathrm{MgF}_{2}$ windows. Quercitrin, the dominant flavonoid in Arabidopsis seeds, has a VUV-UV absorption spectrum that closely matches that of DNA, with additional absorbance in the UVA, while the absorption spectrum of catechin mimics that of protein (Zalar et al., 2007; Zalar, 2010). DNA from the nptII gene, which encodes kanamycin resistance, was exposed with the expectation that it would be completely degraded by solar UV light.

\section{Materials and Methods}

\subsection{Plant materials and seed germination}

With the exception of the fah1-2 mutant (Nottingham Arabidopsis Stock Centre), Arabidopsis seed stocks were from the Versailles Arabidopsis Resource Centre. Tobacco, including Havana PT (pTNH32-70-2), carrying a nptII marker in the chloroplast DNA (Carrer et al., 1993), was a gift from P. Maliga. The PT line was included to provide in planta, multicopy nptII for DNA degradation studies to be described elsewhere. Seed samples were produced in the greenhouse simultaneously for all genotypes of the same species and spread in monolayers behind UV-transparent, $7 \times 7 \times 1 \mathrm{~mm} \mathrm{MgF}_{2}$ windows (Zalar, 2010). Seeds were held in place by a steel plate and spring. Mean sample sizes per window were $16.3 \pm 1.74 \mathrm{mg}$ (standard deviation, s.d.) for Arabidopsis and $20.9 \pm 1.38 \mathrm{mg}$ (s.d.) for tobacco. After return to Earth, the sample carrier was stored desiccated at $4^{\circ} \mathrm{C}$. Seeds were removed from behind the windows in a laminar flow hood with an insect pin that had been coated with 


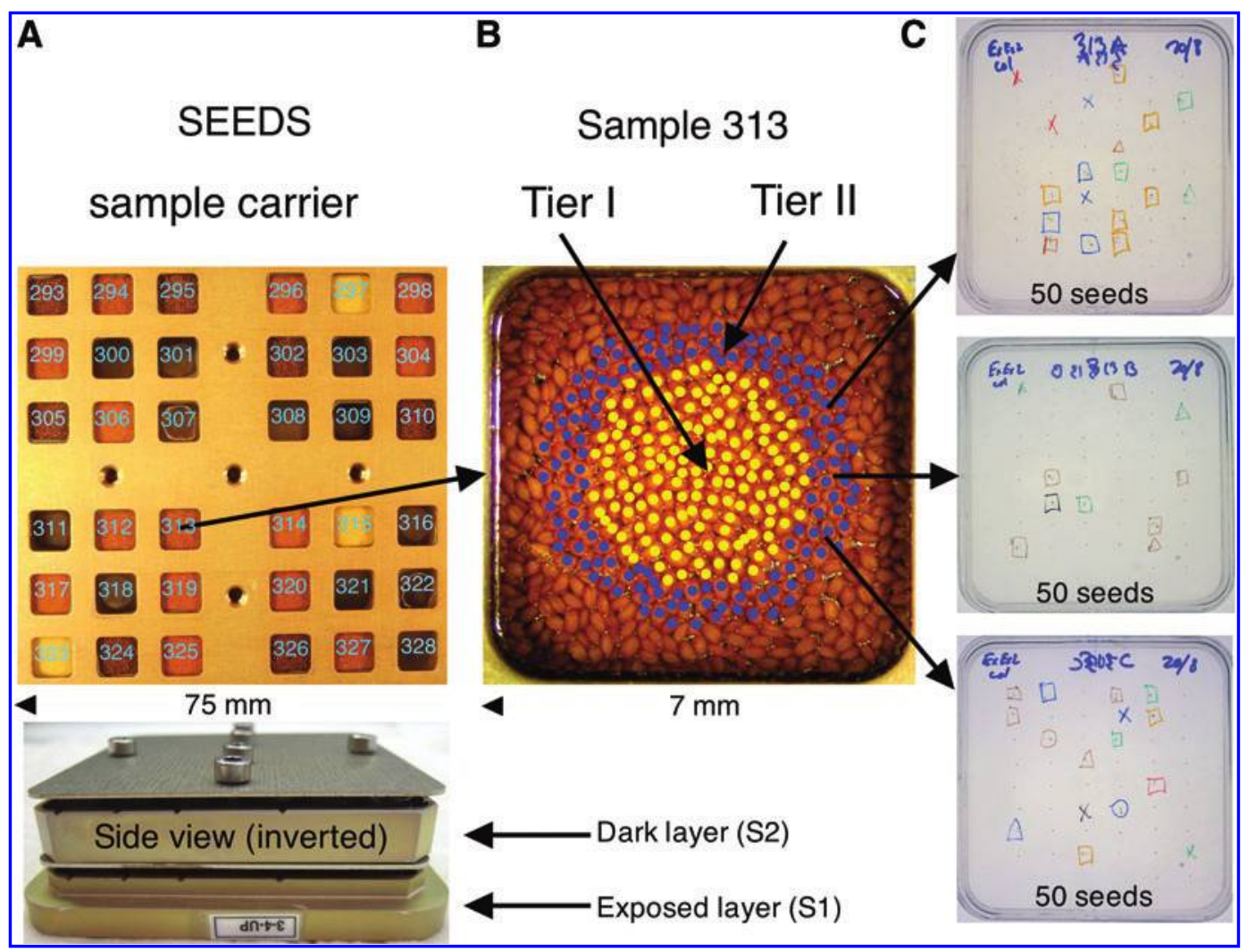

FIG. 2. Experimental layout and sampling. (A, Top) The SEEDS experiment on EXPOSE with sample identification numbers (same orientation as in Fig. 1). Large seeds, tobacco; small seeds, Arabidopsis; yellow seeds, Arabidopsis flavonoid minus mutant (tt4-8). Dark-colored samples include chemical sunscreens and DNA, which is in the center of each group of nine samples. (A, Bottom) side view of the sample carrier, inverted with the exposed layer (S1) downward, before compression of the springs. (B) Enlarged view of a typical seed sample (number 313, Arabidopsis Columbia wild type), seen from outside the $\mathrm{MgF}_{2}$ window. Seeds were held in a monolayer from behind by a steel plate and spring. Yellow dots, tier I; blue dots, tier II. (C) Seeds from each tier (150 for Arabidopsis, 50 for tobacco) were distributed sequentially into three Petri dishes, starting in the center of the window. Petri dishes are shown at the 10-day end point of the germination test, with a symbol marking the time of each germination event. Color images available online at www.liebertonline.com/ast

adhesive from double stick tape. The pin was dipped in sterile water, then touched to a seed, which adhered to the film of water but not to the adhesive. Seeds were placed on agar medium, containing $0.8 \%$ agar $(\mathrm{w} / \mathrm{v})$ in deionized water in three Petri dishes (Fig. 2C), according to their position during exposure so that any exposure gradient would be detected in the sequence of seed germination (dish 1: seeds 1, 4, 7, etc.; dish 2: seeds 2, 5, 8, etc.). For Arabidopsis, 150 seeds from each window were sampled in three batches of 50 seeds in each round of experiments (designated tiers I and II). For the larger tobacco seeds, 50 seeds were removed from each tier in the same fashion and placed sequentially onto a single Petri dish. Each experiment included lab controls (L0) that had been stored at $4^{\circ} \mathrm{C}$. Petri dishes were maintained at $8^{\circ}$ $\mathrm{C}$ in the dark for $78 \mathrm{~h}$ to attain homogenous imbibition before the start of germination. Germination took place at $22^{\circ} \mathrm{C}$, under $16 \mathrm{~h}$ of $4 \mu \mathrm{E} \mathrm{m}^{-2} \mathrm{~s}^{-1}$ light from white compact fluorescent lamps (Philips Softone SW) and red LED lamps (Philips E27G50R). It was monitored hourly during periods of rapid change. Root emergence was scored under $14 \times$ magnification and recorded on the back of the Petri dish with a colored symbol for each time point (Fig. 2C). Samples were identified by numbers. Determination of germination was thus blind, except for the flavonoid-lacking $t t 4-8$ seeds, which were obvious due to their yellow color. Seedlings were removed from Petri dishes and transferred to the greenhouse in squares of agar to avoid damage to the young roots.

\subsection{Exposed chemicals}

Chemical samples included two flavonoid UV screens found in the Arabidopsis seed coat and DNA from the nptII gene, which encodes kanamycin resistance. The dominant Arabidopsis seed flavonoid (Routaboul et al., 2006) is quercitrin (quercetin-3-O-rhamnoside, Sigma-Aldrich). Catechin $\left(+3,3^{\prime}, 4^{\prime}, 5,7\right.$,-pentahydroxyflavan, Extrasynthese, Genay, France) is also an important flavonoid in Arabidopsis. From a $1.5 \mathrm{mg} \mathrm{mL}^{-1}$ solution in $50 \%(\mathrm{v} / \mathrm{v})$ methanol (HPLC grade), $10 \mu \mathrm{L}$ of each flavonoid was air-dried on the inside (center) of each of two $\mathrm{MgF}_{2}$ windows, which corresponded roughly to the tier I+ II surface area. Postflight UV absorption spectroscopy (Shimadzu HPS-2000) was performed on these dry films adhering to the inside of the sample windows (in their original positions in the sample carrier).

The DNA sample of the nptII gene was synthesized from a bacterial plasmid template with the polymerase chain 
reaction (PCR) and the following primers: 5'-GAACAA GATGGATTGCACGC-3' and 5'-AGAAGGCGATAGAAGG CGATGC-3', which produced a 773 base pair (bp) fragment (nucleotide 7 to 780 ) from the $795 \mathrm{bp}$ coding region of $n p t I I$. The PCR product was purified with the QIAquick PCR purification kit (Qiagen, France). PCR conditions included an initial denaturation step at $95^{\circ} \mathrm{C}$ for $5 \mathrm{~min}$, followed by 35 amplification cycles consisting of $1 \mathrm{~min}$ at $95^{\circ} \mathrm{C}$ (denaturation), $1 \mathrm{~min}$ at $55^{\circ} \mathrm{C}$ (annealing), and $2 \mathrm{~min}$ at $72^{\circ} \mathrm{C}$ (extension), for 35 cycles, followed by a final extension at $72^{\circ} \mathrm{C}$ for $5 \mathrm{~min}$. Each of four $\mathrm{MgF}_{2}$ windows received $10 \mu \mathrm{L}$ of a $50 \mu \mathrm{g}$ $\mathrm{mL}^{-1}$ solution of this PCR product in ultrapure $\mathrm{H}_{2} \mathrm{O}$. After exposure, DNA was resuspended in $2 \times 20 \mu \mathrm{L}$ of TE buffer (10 mm Tris, $2 \mathrm{~mm}$ EDTA). DNA survival was qualitatively determined by PCR and the above primers for the $773 \mathrm{bp}$ reaction product (nucleotides 7 to 780 ), as described above. The presence of a $110 \mathrm{bp}$ internal fragment (nucleotides 79 to 189) was assayed with the above reaction conditions, with primers 5'-AGACAATCGGCTGCTCTGAT-3' and 5'-CTCG TCCTGCAGTTCATTCA-3'. PCR products were analyzed by gel electrophoresis in $1.2 \%(\mathrm{w} / \mathrm{v})$ agarose, followed by ethidium bromide staining.

Further search for biologically active DNA made use of homologous recombination in Acinetobacter baylyi (strain BD413), between exposed nptII DNA and a defective copy of nptII, carried by plasmid pMR7. The defect is a $10 \mathrm{bp}$ deletion starting at coding sequence position 5999 (de Vries and Wackernagel, 1998; Tepfer et al., 2003). There were 520 bp between the start of the surviving fragment and the beginning of the deletion. Thus, the $110 \mathrm{bp}$ nptII fragment, detected by PCR after exposure to complete space conditions (see Results), did not include the $10 \mathrm{bp}$ deletion.

\subsection{Temperature and pressure conditions}

The temperature in the sample carrier in space fluctuated 16 times during each of the 558 days of exposure, in accordance with illumination changes during the $91 \mathrm{~min}$ orbital period. High-temperature periods $\left(30-40^{\circ} \mathrm{C}\right.$ for $\mathrm{ca} .40$ days) alternated with low-temperature periods $\left(-5^{\circ} \mathrm{C}\right.$ to $-10^{\circ} \mathrm{C}$ for ca. 20 days) due to changes in the orbital plane of the ISS. The lower limit was determined by heaters that were activated at $-12^{\circ} \mathrm{C}$. Exceptions were recorded, which were the result of power loss during a low-temperature period and repositioning of the ISS for solar panel installation. The minimum recorded temperature was $-25^{\circ} \mathrm{C}$ and the maximum $+61^{\circ} \mathrm{C}$. Temperature fluctuations produced approximately 200 transitions across $0^{\circ} \mathrm{C}$, with uncertainty due to loss of $25 \%$ of the data. Temperatures were uniform over the two levels of samples. Temperatures in the ground simulation mimicked temperatures in space, with temperatures kept below $30^{\circ} \mathrm{C}$ during the UV exposure (see below). Pressure in space varied, depending on the orientation of the ISS, between $10^{-7}$ and $10^{-4} \mathrm{~Pa}$, according to estimates made with data from the pressure gauge on the MEDET facility, adjacent to EXPOSE on the ISS.

\subsection{Light conditions}

The patterns of temperature change reflect changes in exposure to sunlight, which was determined by shadow mapping (RedShift, Brussels), solar light measurements from the SORCE satellite, and detailed positional information for the ISS (NASA). The UVA, B, C dose for the entire mission was first calculated by accounting only for shadows and reflections from dynamic structures, such as solar arrays and the position of the ISS, but not accounting for static structures, such as open shutters. A total dose of $1.23 \times 10^{6} \mathrm{~kJ} \mathrm{~m}^{-2}$ $\left(\mathrm{UVA}_{315-400 \mathrm{~nm}}=9.58 \times 10^{5} \mathrm{~kJ} \mathrm{~m}{ }^{-2} ; \mathrm{UVB}_{280-315 \mathrm{~nm}}=1.95 \times 10^{5}\right.$ $\mathrm{kJ} \mathrm{m}{ }^{-2} ; \mathrm{UVC}_{100-280 \mathrm{~nm}}=7.76 \times 10^{4} \mathrm{~kJ} \mathrm{~m}^{-2}$ ) was thus calculated. This UV dose was then corrected for shadows and reflections from static objects, including the Columbus module, shutters, window frames, and so on, and exposure was simulated at 24 positions within each window. In a typical sample, exposure falloff within tier I was $<10 \%$, and it was $<20 \%$ within tier II. The total UV dose is thus best summarized by using fully corrected values for the center of each exposed window: $\mathrm{UVA}_{315-400 \mathrm{~nm}}=5.78 \times 10^{5} \mathrm{~kJ} \mathrm{~m}^{-2}$; $\mathrm{UVB}_{280-315 \mathrm{~nm}}=1.17 \times 10^{5} \mathrm{~kJ} \mathrm{~m}^{-2} ; \mathrm{UVC}_{100-280 \mathrm{~nm}}=4.62 \times 10^{4} \mathrm{~kJ}$ $\mathrm{m}^{-2}$, for a total $\mathrm{UV}_{100-400 \mathrm{~nm}}$ exposure of $7.4 \times 10^{5} \mathrm{~kJ} \mathrm{~m}^{-2}$. This exposure estimation does not take into account transmission loss through the $\mathrm{MgF}_{2}$ windows (see below).

$\mathrm{UV}_{200-390}$ spectroscopy (not shown) through $\mathrm{MgF}_{2}$ windows that had not been in contact with seeds showed that they were initially transparent to solar UV light down to $110 \mathrm{~nm}$, with no reduction in transmission (measured at 200$300 \mathrm{~nm}$ ) after exposure. However, the seeds of both species left a residue on the inside of the windows that caused a transmission loss of about $12 \%$ at $390 \mathrm{~nm}$ and $46 \%$ at $200 \mathrm{~nm}$ (in a typical window), indicating that the total exposure to UV was less than the value given above. The time course of transmission loss is not known. Thus, transmission decreased during exposure, but not due to inherent changes in the windows.

Seeds in the ground simulation (G1) received $5.8 \times 10^{5} \mathrm{~kJ}$ $\mathrm{m}^{-2}$ of $\mathrm{UV}_{200-400 \mathrm{~nm}}$ light from a solar lamp (SOL 2000, Dr. Hönle UV technology, Gräfelfing, Germany). UV treatment was performed over a period of 1 month, following the temperature plus vacuum simulation.

\subsection{Radiation conditions}

Particle radiation was measured by passive detectors built into the EXPOSE sample carriers 1 and 2, which were adjacent to the SEEDS experiment in carrier 3. The dose was $53.1 \mathrm{mGy}$ galactic cosmic rays (583 days of exposure), $237.7 \mathrm{mGy}$ of South Atlantic Anomaly protons (558 days of exposure), and $4.8 \mathrm{mGy}$ outer radiation belt electrons (558 days of exposure). The total dose behind the outer (S1) $\mathrm{MgF}_{2}$ windows was $295.6 \mathrm{mGy}$. The dark (S2) and exposed (S1) layers received the same dose of galactic cosmic rays, but lower-energy particles (electrons and protons) were received primarily by the exposed layer. The dark samples on the starboard side (away from the Columbus module) received approximately $25 \%$ more lower-energy particles than samples on the port side, closer to Columbus, probably due to a solar wind shadow, which is similar to the UV shadow caused by Columbus and nearby structures. Ionizing radiation doses are low on the ISS due to protection from Earth's magnetic field.

\subsection{Statistical analysis}

$P$ values were calculated by using the Wilcoxon-MannWhitney test in the graphing and statistics program, KaleidaGraph. $P>0.05$ was considered significant. 


\subsection{Spaceflights and seed storage}

The SEEDS experiment was part of EXPOSE-E, which was launched by NASA on 7 February 2008 (flight STS-122), with a return on 12 September 2009 (flight STS-128 Cal). Sample de-integration took place on 3 December 2009. Pre- and postflight temperatures were ambient; preflight seeds were stored in EXPOSE under nitrogen, but postflight they were in ambient atmosphere. After de-integration, seeds were stored in the sample carrier (Fig. 2), desiccated at $4^{\circ} \mathrm{C}$.

\section{Results}

\subsection{Seed germination}

Seeds were returned to Earth after 558 days of exposure on the EuTEF platform (Fig. 1). The deleterious effects of space travel were quantified by studying their germination. Exposure artifacts were assessed, including edge effects (shading from the edges of the sample windows), position effects (shading from nearby objects), and seed overlap effects (shading from adjacent seeds). Position effects were evaluated for each seed type by comparing similar samples at three dispersed positions on the exposed surface (Fig. 2A). To estimate edge effects, seeds were removed starting at the center of the seed monolayer and working outward in a spiral (Fig. 2B). Germination was scored microscopically as root emergence, with observations made hourly during periods of rapid change. It was expressed as the accumulation of observations of root emergence over time and presented as the mean of the three, 50-seed samples (Figs. 3 and 4). Survival was defined as germination that produced morphologically intact, growing plants, scored at the last time point in the germination curve, 10 days after the beginning of imbibition.

An important concern was to assess artifacts due to edge and position effects. Within each tier, no patterns of germination could be attributed to the initial seed position behind the $\mathrm{MgF}_{2}$ window; that is, for a given Petri dish, seeds closer to the center of the $\mathrm{MgF}_{2}$ window did not germinate later than seeds away from the center (Fig. 2C). However, in the Arabidopsis Ws-2 wild type and the tt4- 8 mutant, germination kinetics and overall survival were improved in tier II, relative to tier I (Fig. 3A, 3D). Germination differences between tiers I and II were generally smaller for the other genotypes (Fig. 3), which indicates that edge effects were largely avoided by restricting the sampling to tiers I and II. Data from tiers I and II were thus pooled (Fig. 4), in keeping with the data in Fig. 3 and the prediction from shadow mapping that light falloff was $<20 \%$ in tier II.

In some experiments, germination and survival differed among the three 150-seed samples of each seed type, dispersed on the surface of the SEEDS carrier (e.g., Fig. 3C, 3D, $3 F)$. Since these position effects were not observed in the S2 dark layer (Fig. 5), they were probably due to variable UV microenvironments on the exposed surface, caused by shadows and reflections from nearby objects. However, position variability was greater in Arabidopsis Ws and in tobacco than in Arabidopsis Columbia, which suggests that other factors (including the magnitude of germination, transmission loss in the $\mathrm{MgF}_{2}$ windows, and conditions in individual Petri dishes) could have contributed to the apparent position effects. Despite these uncertainties, positional effects did not preclude finding statistically valid differences among the genotypes by using data pooled from the three positions tested (Fig. 4).

Modeling (RedShift, Brussels) of the shadow effects predicted an exposure gradient over the exposed samples from left (low) to right (high) and another from bottom (low) to top (high), as the seed sample carrier is presented in Fig. 2A. Correction (not shown) of the raw germination data, with use of the shadow map-derived value for the center of each sample position, did not alter the conclusions drawn from the uncorrected data. Thus, the data presented in Fig. 3 are not corrected for uneven illumination.

Survival results (maximum seed germination that produced intact plants) were pooled from tiers I and II and from the three positions on the surface of EXPOSE (Fig. 4). Pooled data for $t t 4-8$ and tobacco were only corrected for differences in lab control germination, evident in the uncorrected L0 mean data (Fig. 3D). Correction factors were 1.087 for tobacco and 1.064 for $t t 4-8$. The sample size (batches of 50 seeds) for each genotype was 900 seeds in Arabidopsis and 300 in tobacco. The Havana and PT tobacco survival results were also pooled, since no phenotype is associated with PT, and there was no statistical difference in germination between the two lines $(P=0.559)$.

The germination kinetics and survival of wild-type seeds varied with genotype (Figs. 3 and 4 ). The highest survival was $44 \%$ ( $n=1 \times 50$ seeds) in tobacco (Havana), tier II, position 293 (Fig. 3F). Among the wild types, WS was less resistant than Columbia (Fig. 3A, 3B, 3D, 3E, Fig. 4), and survival in tobacco was similar to that in Columbia (Fig. 3B, 3C, 3E, 3F, Fig. 4). Arabidopsis mutants lacking sunscreens were less resistant to full exposure than the corresponding wild types (Figs. 3 and 4). No tt4-8 (flavonoid minus) seeds germinated in tier I (Fig. 3A, Fig. 4). Lack of sinapate ester sunscreens (fah1-2 mutant) was also associated with reduced germination, but to a lesser extent than in tt4-8 (Figs. 3 and 4). Survival thus varied with ecotype and was improved by UV screens.

\subsection{Radiation effects}

Comparison between the dark layers in the ground simulation (G2) and those on the ISS (S2) allowed an estimate of galactic cosmic radiation effects in the dark layer in space, since the ground simulation dark layer received equivalent space vacuum and temperature but was spared the cosmic radiation. (Solar ionizing radiation was largely stopped by the $\mathrm{S} 1$ layer.) The onset of germination was delayed by $7 \mathrm{~h}$ in Arabidopsis Columbia in the dark layer exposed to galactic cosmic radiation, compared to the lab control and ground simulations (Fig. 5). In tobacco, germination was delayed by $14 \mathrm{~h}$. However, total survival in wild-type Arabidopsis and tobacco (pooled Havana+PT) did not differ in the dark layers on the ISS and on the ground (Fig. 6). Thus, galactic cosmic radiation was a minor, but measurable, liability during the 18-month exposure. Nevertheless, it could cause severe damage during longer journeys through space (Kranz et al., 1990; Wei et al., 2006). In contrast to the other genotypes, survival of the $t t 4-8$ mutant (lacking flavonoids) was reduced in the dark layers, both in space and on the ground (Fig. 6), which possibly reflects an additional role for flavonoids in responses to temperature fluctuations $\left(-25^{\circ} \mathrm{C}\right.$ to $\left.+61^{\circ} \mathrm{C}\right)$. 

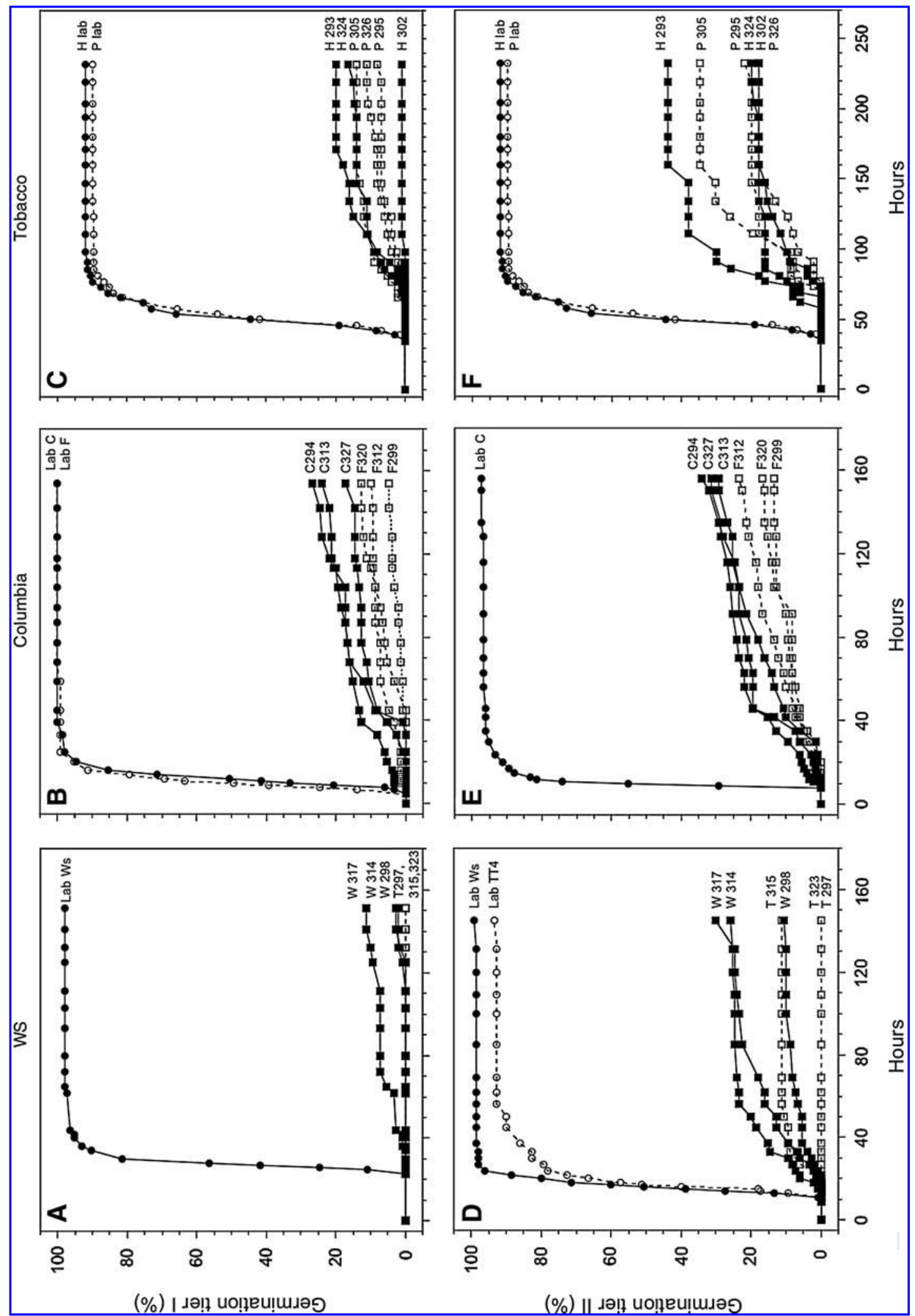

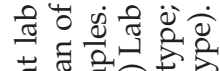

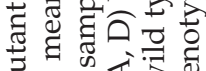

¿

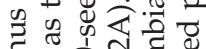

. छ

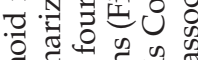

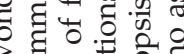

त क ज्ञ

के क्ष

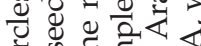

•

늄

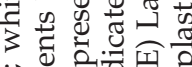

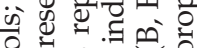

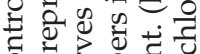

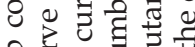

즈 ᆰ。

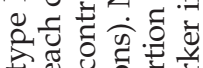

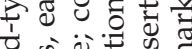

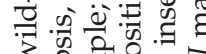

3 을.

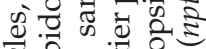

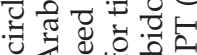

ช

I I

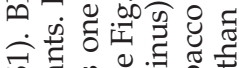

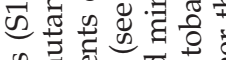

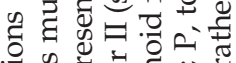

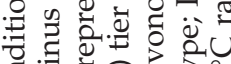

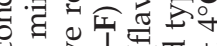

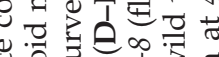

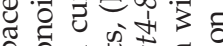

की

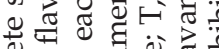

용

द्व

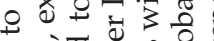

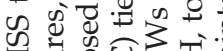

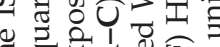

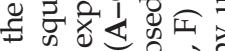

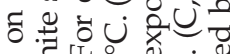

ठ

它的至泀

ช

\& 0 क क

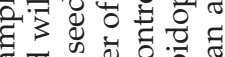

๘

苍旅

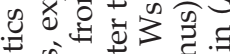

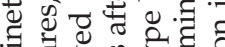

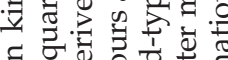

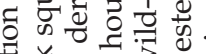

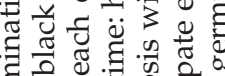

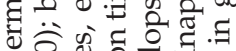

৩已串司

ल क 己.

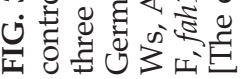




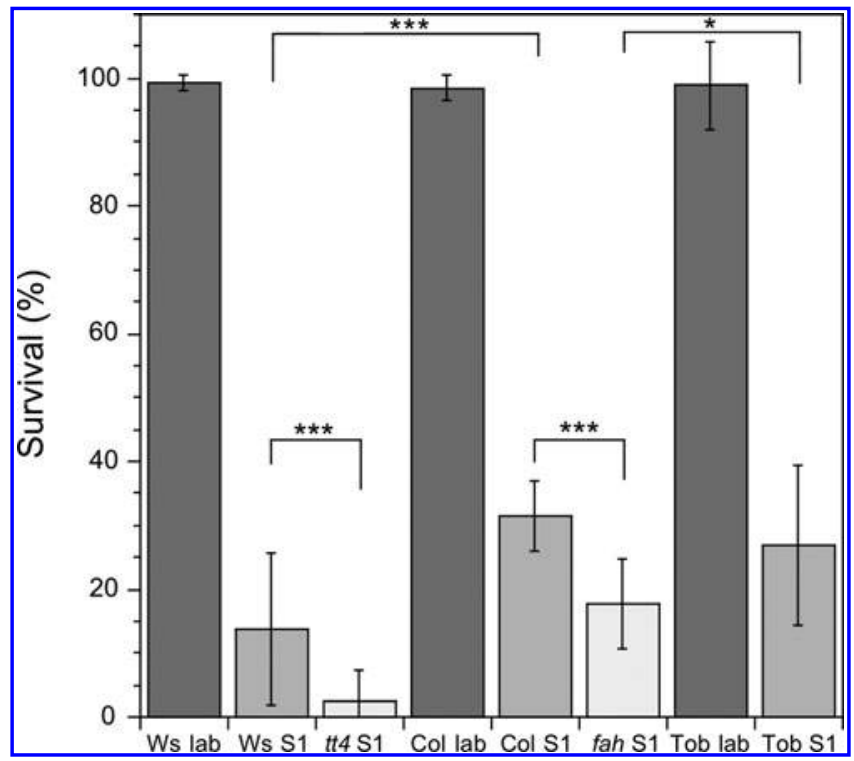

FIG. 4. Survival according to genotype. Sample repeats were pooled by using each 50-seed sample from Fig. 3 (sample repeats and tiers I, II). To enable comparison, pooled data were corrected for $t t 4-8$ (multiplication factor, 1.064) and tobacco (multiplication factor, 1.087), thus normalizing for inherently lower germination in the respective lab controls (Fig. 3C, 3D). Both flavonoid- and sinapate-lacking mutants were less resistant than the corresponding wild types, and the Ws wild type was less resistant than Columbia. Data are presented as means \pm s.d. ${ }^{*} P<0.05,{ }^{* * *} P<0.001$. $n=6 \times 50$ for Arabidopsis lab controls; $n=8 \times 50$ for tobacco lab controls; $n=18 \times 50$ for Arabidopsis exposed seeds; $n=6 \times 50$ for tobacco-exposed seeds. The total calculated $\mathrm{UV}_{100-400 \mathrm{~nm}}$ exposure was $7.4 \times 10^{5} \mathrm{~kJ} \mathrm{~m}^{-2}$.

\subsection{Temperature and vacuum effects}

Survival was similar in the Ws lab control (L0) and in the space dark control (S2), which indicates that exposure to space temperature and vacuum did not diminish survival (Fig. 6). However, survival was reduced in the $t t 4-8$ seeds exposed to space temperature and vacuum WS (S2) $98.1 \pm 2.2 ; n=18 ; t t 4$ (S2) $84.6 \pm 7.4 ; n=18 ; P=<0.0001$. In contrast, survival in tobacco increased (Fig. 6) by six percentage points in seeds exposed to space vacuum and temperature (G2): lab control (L0), 91.1\% $16.33, n=8 \times 50$; ground simulation (G2) $97.2 \% \pm 2.33 ; n=12 \times 50 ; P=0.015$. Space temperature and vacuum thus stimulated survival in tobacco, perhaps due to better desiccation in space. We conclude that after 18 months of exposure, radiation and vacuum plus temperature effects could be measured, but they were minor, species dependent, and not necessarily deleterious. Data were corrected for tt4-8 (multiplication factor, 1.064) and tobacco (multiplication factor, 1.087) to normalize for inherently lower germination in the respective lab controls (Fig. 3C, 3D, 3F). Data from the three repeats of each genotype were pooled, and tobacco data include Havana plus the PT insertion line.

\subsection{Phenotype of survivors}

To assess the morphology and fertility of the survivors at the end of the 10-day germination test, 10 Arabidopsis plants or five tobacco plants (or ungerminated seeds, when germination was low), representative of each sample of 50 seeds, were transferred on blocks of agar to soil in the greenhouse and grown through seed set. Morphological abnormalities were not evident in Arabidopsis and tobacco in vitro, and the majority of the plants of both species were capable of growth and seed set in the greenhouse. However, slow growth and reduced seed set were common in Arabidopsis exposed to space UV (S1), but not in the dark layer (S2). In tobacco, slow growth and reduced seed set occurred in seven out of the 101 plants grown to maturity from exposed seeds (S1), with one plant dying upon transfer from agar to soil. The reduced effects of exposure in tobacco, compared to Arabidopsis, could be due to the more developed endosperm in tobacco, which provides better shielding of the embryo, and perhaps to tobacco's larger, more redundant genome.

\subsection{Phenotype in the first sexual generation after exposure}

Seeds were sown from Arabidopsis Ws (S1) tier I survivors of full space exposure, the most affected by exposure (Fig. 3A). All 44 seeds germinated, and 42 produced fertile plants with a normal seed set. One plant was of small stature, and one plant produced only one seed. No morphological aberrations were observed. Thus, the reductions in growth and fertility seen in the survivors of full exposure to space largely disappeared in the first sexual generation after exposure. A similar result was obtained in tobacco. Survival thus appears to have been an "all or none" phenomenon; the survivors' genome was not irreparably damaged, and failure of germination was likely due to general UV damage due to other factors, including a lethal accumulation of free radicals, destruction of membranes, or massive damage to ribosomes (Casati and Walbot, 2004).

\subsection{Effects of solar UV on flavonoid UV screens}

Flavonoids contributed to the resistance of Arabidopsis seeds to UV light (Figs. 3 and 4), but to be effective, their shielding capacity should not be lost during exposure. Comparison of $\mathrm{UV}_{200-390 \mathrm{~nm}}$ absorption by quercitrin and catechin in the fully exposed S1 layer and the dark S2 layer revealed changes in UV absorption in flavonoids from the S1 layer, including a loss of features, a shift to lower wavelengths, and a 30\% increase in the capacity of both flavonoids to absorb energy in the region between 200 and $400 \mathrm{~nm}$ (Fig. 7). Protection was not lost in the DNA-absorbing regions (200 and $260 \mathrm{~nm}$ ), but there was a pronounced loss of UVA absorption in the exposed (S1) quercitrin.

\subsection{Effects of solar UV on nptII DNA}

The polymerase chain reaction (PCR) was used to monitor survival of naked DNA encoding a $773 \mathrm{bp}$ region of nptII, a bacterial kanamycin resistance gene. In DNA from the fully exposed S1 layer, the entire $773 \mathrm{bp}$ nptII fragment was not detected by PCR (not shown), but an internal (110 bp) fragment was amplified (Fig. 8A) with another primer set designed to amplify nucleotides 79-189. Strong amplification was detected in two of the four DNA samples. DNA amplification of this short fragment was therefore verified in a second round of PCR by using $1 \mu \mathrm{L}$ from the first round. The 

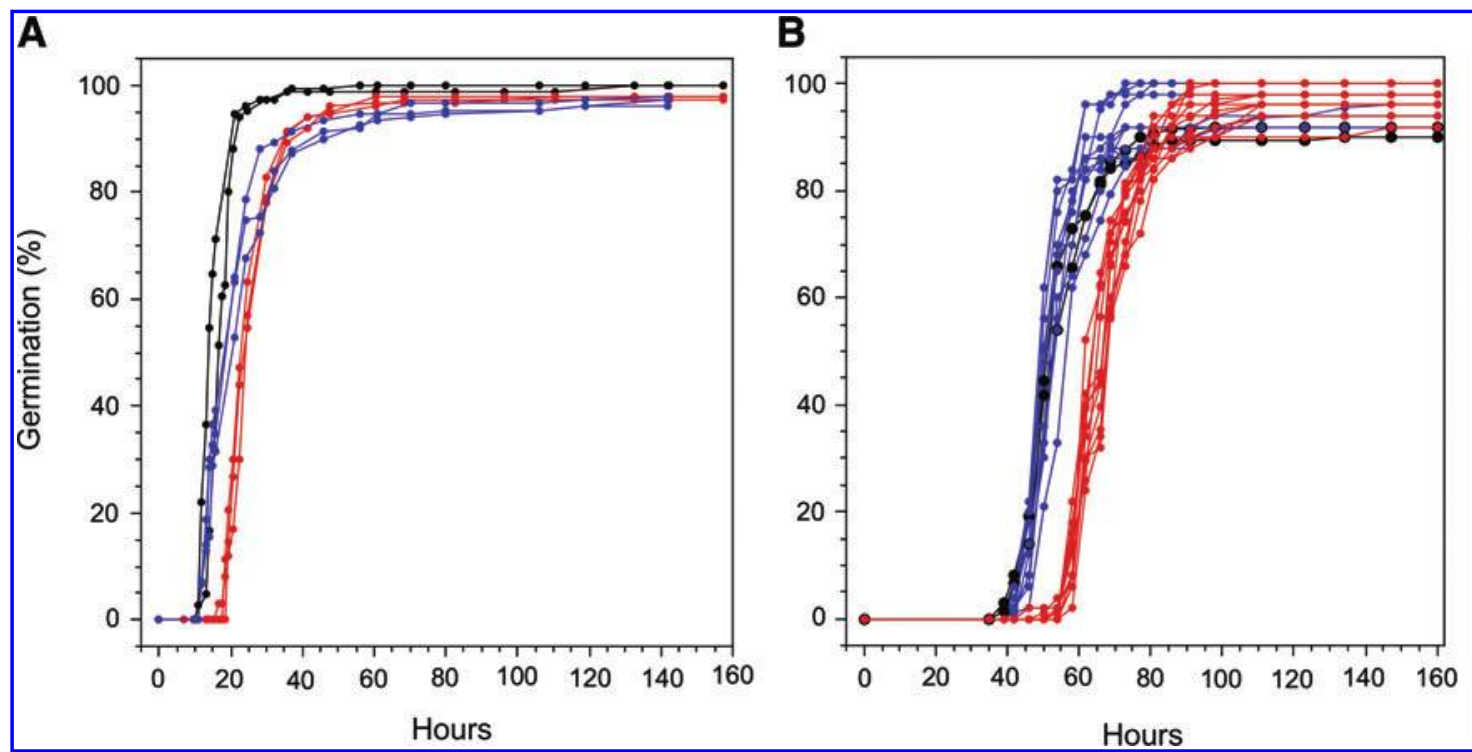

FIG. 5. Cosmic radiation and seed germination kinetics. Effects of cosmic radiation were assessed by comparing germination kinetics in seeds from the dark layer in space (S2), which received galactic cosmic radiation, and seeds from the dark layer in the ground simulation (G2), which did not. (A) Germination kinetics in Arabidopsis (Columbia). Blue curves: seeds from the ground simulation (G2) dark layer, without UV and radiation but with space vacuum and temperatures; red curves: seeds from the ISS dark layer (S2), without UV but exposed to galactic cosmic radiation; black curves, lab controls (L0). Galactic cosmic radiation exposure was associated with a $7 \mathrm{~h}$ delay in germination. Each curve represents accumulated germination events, expressed as the mean of three samples, each involving 50 seeds. (B) Same as (A), but with tobacco seeds (Havana plus PT), showing a 14h delay in germination. Each curve represents a single sample, comprised of 50 seeds. Color images available online at www.liebertonline.com/ast

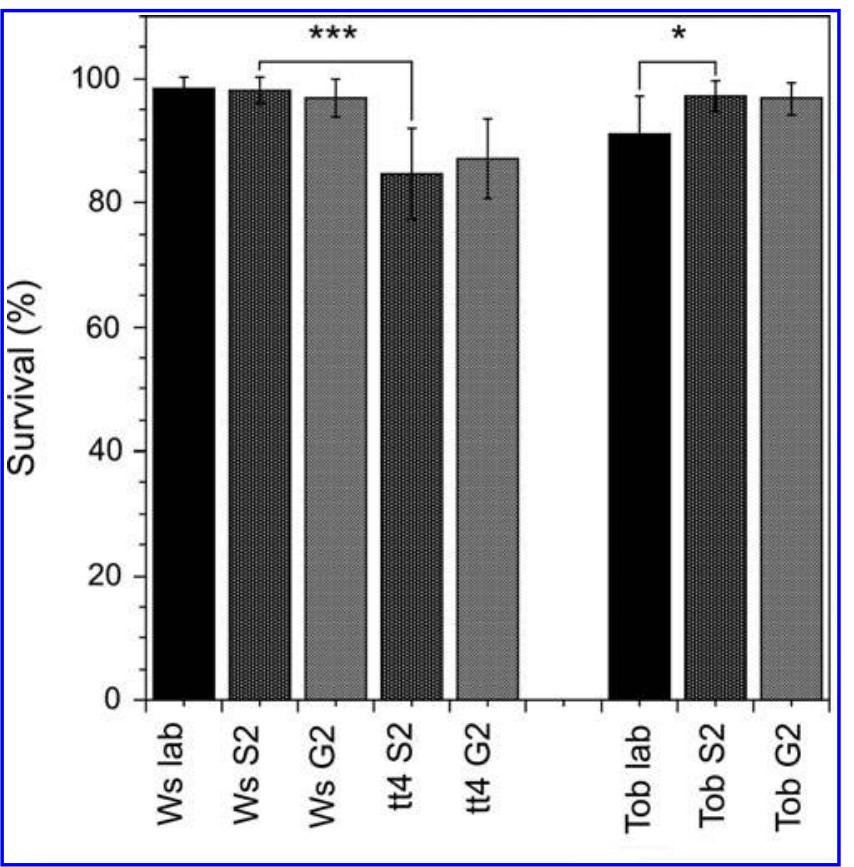

FIG. 6. Effects of cosmic radiation, space vacuum, and temperature on survival. Black columns, lab controls (L0); gray columns, dark controls in space (S2); light gray columns, ground dark controls (G2). Survival was similar in the dark in space and in the corresponding ground simulation (S2 vs. G2) for Arabidopsis Ws (wild type), tt4-8 (flavonoidlacking) and tobacco (Tob), showing that galactic cosmic radiation did not diminish survival. ${ }^{*} P<0.05$, ${ }^{* * *} P<0.001$. second round produced strong amplification of the $110 \mathrm{bp}$ fragment in all exposed samples but not in the negative control (not shown). The DNA samples were thus partially degraded, but given the presence of weak signals in two of the four samples, we can infer that template was probably limiting, e.g., that few intact copies of the 79-189 region survived exposure to solar UV light. In contrast, DNA from the S2 layer, which was protected from UV, provided a consistently strong amplification template for the $110 \mathrm{bp}$ fragment (Fig. 8A). Amplification of the $773 \mathrm{bp}$ fragment occurred, and the template DNA was physically intact, as shown by agarose gel electrophoresis (Fig. 8B).

The survival of biologically active nptII DNA was also assessed by using homologous recombination between exposed nptII and a resident, defective nptII, carried by pMR7 in Acinetobacter baylyi strain BD412 (de Vries and Wackernagel, 1998). Dark layer (S2) DNA (15 ng) from sample position 285 was tested for the ability to confer kanamycin resistance, that is, to rescue the mutation in the resident nptII, producing $10^{6}$ colony-forming units on medium containing kanamycin. In contrast, no resistant colonies formed when using a 20-fold excess of DNA from the exposed (S1) layer. This biological test for DNA survival thus confirmed the above PCR results: DNA exposed to UV was largely degraded and biologically inactive, but DNA survived in the dark layer, protected from UV light.

\section{Discussion}

\subsection{Experimental variability and seed survival}

Variables that might explain heterogeneous responses in the seed population include seed genetic makeup, size, 

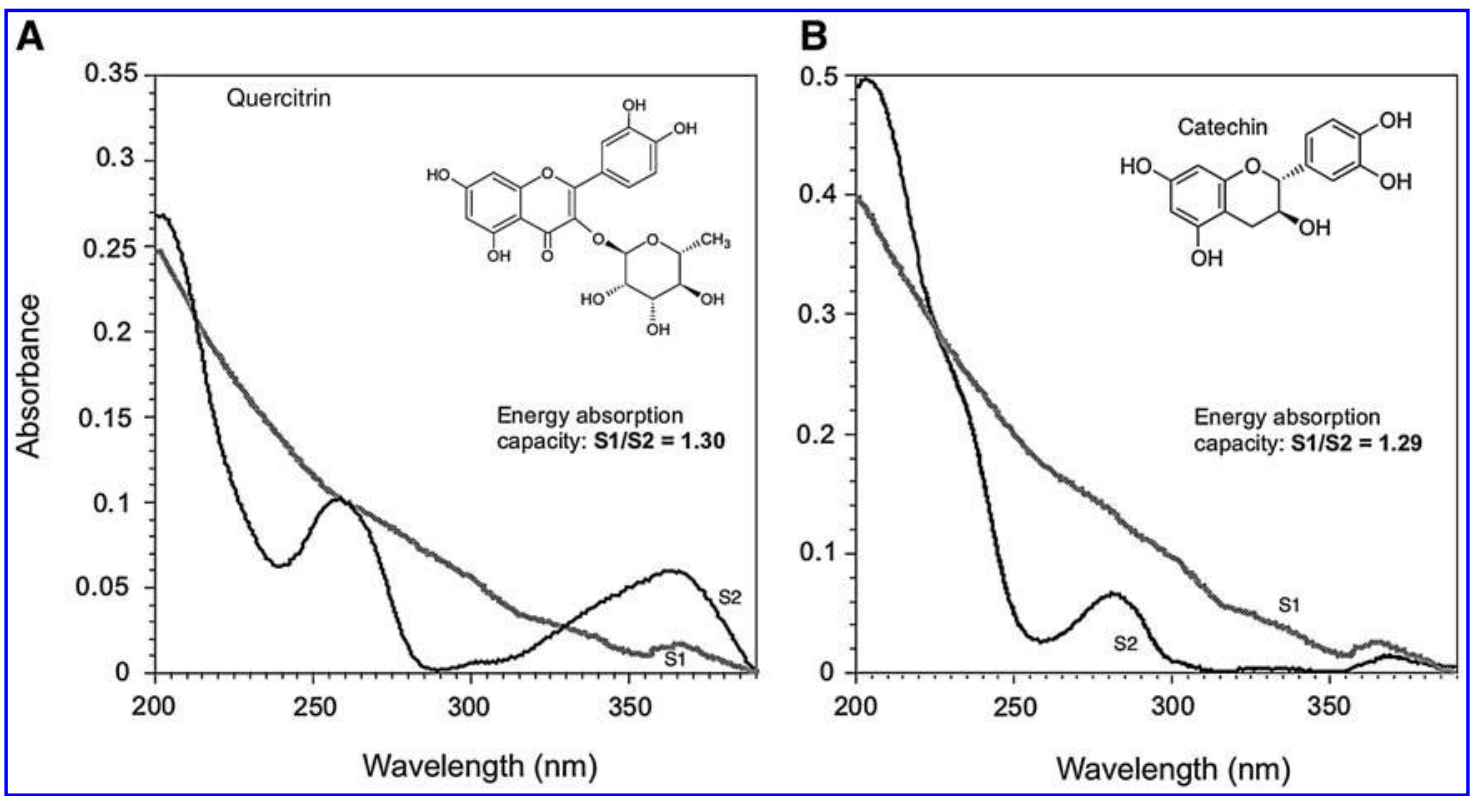

FIG. 7. Effects of solar UV light on two Arabidopsis flavonoids, examined with UV absorption spectroscopy (dark lines, S2 dark layer; gray lines, S1 fully exposed layer) (A) Quercitrin. (B) Catechin. Structural features were lost, but overall absorption capacity was retained.

orientation, changes in $\mathrm{MgF}_{2}$ window transmission, and interseed shading. For instance, Arabidopsis seeds are ovoid, so seed overlap might protect the shoot or root meristematic (growing) zones at each extremity. However, differences in seed numbers per window (seed density) were not quite significant $(P=0.06575, \alpha=0.05)$. Furthermore, the increased sensitivity of both sunscreen-lacking mutants to solar UV also argues against the significance of this potential artifact, and inter-seed shading is less likely in tobacco seeds, which are closer to spherical. The large sample sizes should

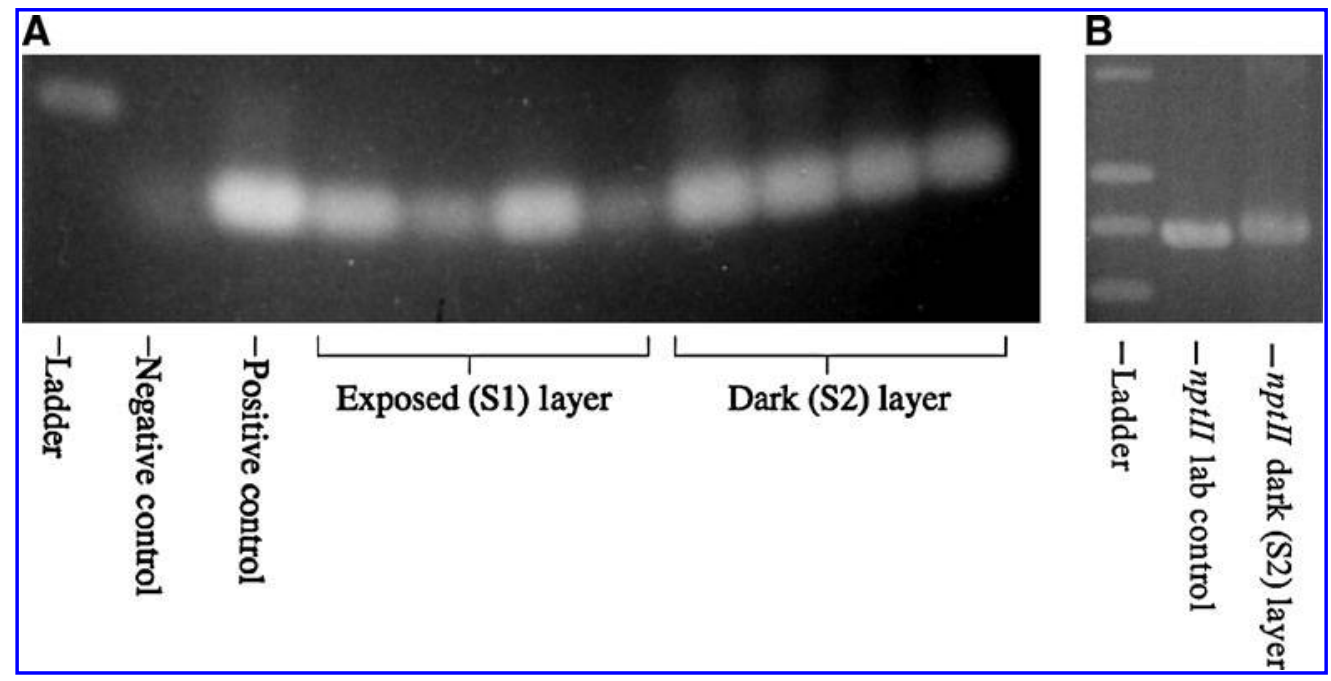

FIG. 8. Effects of solar UV light on $n p t I I$ DNA. (A) A 110 bp region in the $n p t I I$ gene coding sequence was amplified by PCR, indicating that part of the nptII gene survived exposure to full space conditions, including solar UV. PCR of the same samples when using the whole $773 \mathrm{bp}$ nptII fragment produced no reaction products (not shown). Amplified DNA products were separated according to their molecular weight by gel electrophoresis, stained with ethidium bromide, and visualized with $\mathrm{UV}_{312 \mathrm{~nm}}$, which causes DNA complexed with ethidium bromide to fluoresce visible light. The white spots in the figure represent DNA molecules that migrated in the agarose gel at a similar molecular weight. Two of the samples from the S1 layer were weak; thus one $\mu \mathrm{L}$ from each reaction was used in a second round of PCR, producing strong accumulation of PCR products in all samples, as in the positive controls. One microliter from the negative control (without DNA) produced no reaction products (results not shown). Ladder designates a molecular weight marker at 200 bp. (B) Gel electrophoresis (1\% agarose) of lab control nptII DNA (5 $\mu \mathrm{L}$ ) or DNA from the S2 layer (5 $\mu \mathrm{L}$, sample 318). The closest molecular weight marker was $800 \mathrm{bp}$. The S2 DNA sample appears to be intact. It also rescued a defective nptII, conferring kanamycin resistance on a soil bacterium, and it was amplified by PCR (see text). 
compensate for differences between individual seeds and their orientation. We conclude that it is unlikely that interseed shading artifacts caused the survival observed, although they could contribute to the variability among repeated samples from different positions (different windows). Similar arguments can be made for the importance of individual genetic differences, seed size, and seed orientation. The deposit of UV-absorbing residues on the inside of the $\mathrm{MgF}_{2}$ windows was variable (results not shown), and it could explain some of the differences among sample repeats. Again, experimental variability did not preclude finding differences among the samples predicted by the biology; mutants lacking UV screens were more sensitive to UV than the corresponding wild types.

\subsection{Radiation effects}

Arabidopsis and tobacco seeds received $253 \mathrm{mGy}$, mostly in the form of protons. Thirteen days of exposure to space radiation produced measurable damage in Arabidopsis seeds (Kranz et al., 1990). In soybean seeds, effective mutagenesis (DNA deletions) was accomplished at fast neutron doses ranging between 4 and $32 \mathrm{~Gy}$ (Bolon et al., 2011). However, cytological aberrations were observed in root tips from rice seeds exposed to space low-orbit radiation for 18 days (Wei et al., 2006). Since our seeds were exposed in the dry state, repair mechanisms were not functioning, and accumulated lesions were repaired only after hydration; however, in the dry state fewer free radicals are expected from the radiolysis of water. We conclude that radiation effects were minor, as expected from the doses received, and that the inhibition of germination in both seed species in the exposed layer (S1) was primarily caused by UV light. However, cosmic radiation most likely caused the species-dependent delay in germination (Fig. 5) observed in the dark layer (S2).

\subsection{UV screens and DNA}

Overall absorbance was maintained after exposure of quercitrin and catechin to solar UV, but it was shifted to shorter wavelengths, presumably due to the degradation of these complex molecules into subunits of variable composition, producing a loss of features in the UV absorption spectra. The retention of overall UV absorbance may explain, in part, the role of flavonoids in the observed survival of Arabidopsis seeds. Retention of absorbance in the 200$400 \mathrm{~nm}$ region is compatible with the protection of DNA and RNA, and it could partially explain the dearth of morphological mutants among the survivors.

Three methods were used to assess DNA survival. The first, agarose gel electrophoresis, showed that the nptII gene was lost in the S1 layer, exposed to UV, but that it survived in the S2 layer, protected from UV. The second method, PCR, failed to amplify nptII in samples from the S1 layer, although a $110 \mathrm{bp}$ subregion was detected (Fig. 8A). Thus, some DNA fragments survived exposure to complete space conditions, but intact genes did not. The third method, a bacterial transformation and recombination assay for biologically active nptII DNA, also gave a negative result for the S1 layer. However, in the S2 layer, which was protected from UV, the DNA was biologically active, that is, it was taken up by a bacterium, and it could correct a $10 \mathrm{bp}$ deletion in a resident nptII.
We conclude that DNA fragments included in, or adhering to, small particles (e.g., clays) blown into the upper stratosphere by winds or volcanoes could survive if they were not exposed to solar UV light. They might later return to Earth as micrometeorites and re-enter the biosphere through bacterial genetic transformation and recombination with resident sequences, as in the nptII model used here. Transfer of such protected DNA might also operate over cosmic distances.

\subsection{Seeds as vectors for life}

To put the observed seed survival in perspective, we can ask whether a seedlike entity could survive the UV exposure associated with transfer between planets, for example, via ejection caused by a meteorite impact on Mars and transfer to Earth. Given an estimated exposure of 1089 solar constant hours for a seed tumbling at random on a direct voyage (4752 h) and the survival of Arabidopsis (Columbia) measured at $32 \pm 5.6 \%$ s.d. ( $n=900$ seeds) after 1913 solar constant hours of exposure, we can speculate that some of the seeds launched from Mars would survive exposure to UV, temperature extremes, and vacuum during the $(6$ months minimum transit time) trip to Earth (Gladman and Burns, 1996; Gladman, 1997). However, they would suffer from other stresses, for example, radiation and pressure plus heating upon ejection from Mars and entry through Earth's atmosphere (Jerling et al., 2008). Furthermore, seeds were immobilized on EXPOSE. A tumbling seed might respond differently to UV radiation. The chances that a naked seed could survive interplanetary transfer are thus difficult to evaluate. The survival observed here nevertheless demonstrates that, although unprotected seeds can resist prolonged exposure to space, UV light is particularly deleterious. If seeds were encased in an opaque matrix (e.g., including water ice), they would be protected from UV light and perhaps some of the shock of ejection and entry. It is thus conceivable, but not proved, that a seedlike entity could survive transfer from Mars to Earth. Comets could be carriers of both water and life (Delsemme, 1998; Hoyle and Wickramasinghe, 1999).

Seeds too damaged to germinate could still release macromolecular components of life into a sterile foreign environment and perhaps jump-start the formation of life (Tepfer and Leach, 2006). Plant seeds harbor endosymbionts, and they sometimes carry free-living bacteria. Thus, seedlike entities could serve as vectors for embedded microorganisms, even if the plant embryo does not survive (Tepfer and Leach, 2006).

Seeds are model extremophiles, whose biological properties might be exploited to build a life-form capable of dissemination in large numbers over long distances through space (Tepfer, 2008). For instance, seed coat UV screens could be augmented (Yu et al., 2003; Chaudhuri et al., 2009), and microorganisms with improved DNA repair could be embedded in seeds, which could be coated with nutritive and protective substances. A $20 \mathrm{~kg}$ payload would carry about one billion Arabidopsis seeds. Plant seeds and embedded microorganisms could thus be used by humans to disseminate Earth's life toward exohabitats, in a reversal (Tepfer, 2008) of the directed panspermia envisioned by Thomas Gold, cited by Sagan (Shklovskii and Sagan, 1966), and by Crick and Orgel (Crick and Orgel, 1973). 


\section{Acknowledgments}

We are grateful to E. Rabbow and the German Aerospace Center (DLR) for ground simulations and sample integration; to T. Beuselinck and C. Van Bavinchove (RedShift Design and Engineering, Brussels) for shadow maps, light exposure simulations, and the Mars-to-Earth exposure estimate; to T. Hoppenbrouwers for the temperature history; to R. Demets, P. Baglioni, and J. Dettmann (ESA) for EXPOSE project management, logistics, and calculations; to the engineers at Kayser-Threde and RUAG for the design and construction of EXPOSE; to NASA for deployment and retrieval; to M. Crespin and M. Romaniuk for greenhouse help; to P. Maliga, C. Chapple, J. de Vries, and W. Wackernagel for biological materials; and to T. Berger and T. Dachev for radiation dosimetry. Funding was from the Centre National d'Études Spatiales (CNES) and from the European Space Agency (ESA). D.T. designed the sample wells, performed the germination, flavonoid, and DNA studies, and analyzed the data; A.Z. prepared the chemical samples and seed monolayers; S.L. carried out computational analysis; D.T. and S.L. initiated the study; D.T. and A.Z. finalized its design; D.T. wrote the paper.

\section{Author Disclosure Statement}

No competing financial interests exist.

\section{Abbreviations}

bp, base pair; ISS, International Space Station; PCR, polymerase chain reaction; s.d., standard deviation.

\section{References}

Anikeeva, I.D., Akatov, Y.A., Vaulina, E.N., Kostina, L.N., Marenny, A.M., Portman, A.I., Rusin, S.V., and Benton, E.V. (1990) Radiobiological experiments with plant seeds aboard the biosatellite Kosmos 1887. Int J Rad Appl Instrum D 17:167-171.

Barman, T. (2007) Identification of absorption features in an extrasolar planet atmosphere. The Astrophysical Journal Letters 661:L191.

Bolon, Y., Haun, W., Xu, W., Grant, D., Stacey, M., Nelson, R., Gerhardt, D., Jeddeloh, J., Stacey, G., Muehlbauer, G., Orf, J.H., Naeve, S.L., Stupar, R.M., and Vance, C.P.(2011) Phenotypic and genomic analyses of a fast neutron mutant population resource in soybean. Plant Physiol 156:240-253.

Carrer, H., Hockenberry, T., Svab, Z., and Maliga, P. (1993) Kanamycin resistance as a selectable marker for plastid transformation in tobacco. Mol Gen Genet 241:49-56.

Casati, P. and Walbot, V. (2004) Crosslinking of ribosomal proteins to RNA in maize ribosomes by UV-B and its effects on translation. Plant Physiol 136:3319-3332.

Chapple, C.C., Vogt, T., Ellis, B.E., and Somerville, C.R. (1992) An Arabidopsis mutant defective in the general phenylpropanoid pathway. Plant Cell 4:1413-1424.

Chaudhuri, K., Das, S., Bandyopadhyay, M., Zalar, A., Kollmann, A., Jha, S., and Tepfer, D. (2009) Transgenic mimicry of pathogen attack stimulates growth and secondary metabolite accumulation. Transgenic Res 18:121-134.

Crick, F.H.C. and Orgel, L.E. (1973) Directed panspermia. Icarus 19:341-346.

de Vries, J. and Wackernagel, W. (1998) Detection of nptII (kanamycin resistance) genes in genomes of transgenic plants by marker-rescue transformation. Mol Gen Genet 257:606-613. de la Torre, R., Sancho, L.G., Horneck, G., de los Ríos, A., Wierzchos, J., Olsson-Francis, K., Cockell, C.S., Rettberg, P., Berger, T., de Vera, J.-P. Ott, S., Martinez Frías, J., Gonzalez Melendi, P., Mercedes Lucas, M., Reina, M., Pintado, A., and Demets, R. (2010) Survival of lichens and bacteria exposed to outer space conditions-results of the Lithopanspermia experiments. Icarus 208:735-748.

Debeaujon, I., Nesi, N., Perez, P., Devic, M., Grandjean, O., Caboche, M., and Lepiniec, L. (2003) Proanthocyanidinaccumulating cells in Arabidopsis testa: regulation of differentiation and role in seed development. Plant Cell 15:2514-2531.

Delsemme, A.H. (1998) Cosmic origin of the biosphere. In The Molecular Origins of Life, edited by A. Brack, Cambridge University Press, Cambridge, UK, pp 100-118.

Eisner, J.A. (2007) Water vapour and hydrogen in the terrestrialplanet-forming region of a protoplanetary disk. Nature 447:562-564.

Gladman, B. (1997) Destination: Earth. Martian meteorite delivery. Icarus 130:228-246.

Gladman, B. and Burns, J.A. (1996) Martian meteorite transfer. Simulation. Science 274:161-162.

Horneck, G., Rettberg, P., Reitz, G., Wehner, J., Eschweiler, U., Strauch, K., Panitz, C., Starke, V., and Baumstark-Khan, C. (2001) Protection of bacterial spores in space, a contribution to the discussion on panspermia. Orig Life Evol Biosph 31:527-547.

Hoyle, F. and Wickramasinghe, N.C. (1999) Comets-a vehicle for panspermia. Astrophys Space Sci 268:333-341.

Jerling, A., Burchell, M., and Tepfer, D. (2008) Survival of seeds in hypervelocity impacts. International Journal of Astrobiology 7:217-222.

Jönsson, K.I., Rabbow, E., Schill, R.O., Harms-Ringdahl, M., and Rettberg, P. (2008) Tardigrades survive exposure to space in low Earth orbit. Curr Biol 18:R729-R731.

Kranz, A.R., Bork, U., Bucker, H., and Reitz, G. (1990) Biological damage induced by ionizing cosmic rays in dry Arabidopsis seeds. Int J Rad Appl Instrum D 17:155-165.

Landry, L.G., Chapple, C.C.S., and Last, R.L. (1995) Arabidopsis mutants lacking phenolic sunscreens exhibit enhanced ultraviolet-B injury and oxidative damage. Plant Physiol 109:11591166.

Li, J., Ou-Lee, T.M., Raba, R., Amundson, R.G., and Last, R.L. (1993) Arabidopsis flavonoid mutants are hypersensitive to UV-B irradiation. Plant Cell 5:171-179.

Pietta, P.G. (2000) Flavonoids as antioxidants. I Nat Prod 63:1035-1042.

Rabbow, E., Horneck, G., Rettberg, P., Schott, J.-U., Panitz, C., L'Afflitto, A., von Heise-Rotenburg, R., Willnecker, R., Baglioni, P., Hatton, J., Dettmann, J., Demets, R., and Reitz, G. (2009) EXPOSE, an astrobiological exposure facility on the International Space Station-from proposal to flight. Orig Life Evol Biosph 39:581-598.

Routaboul, J.-M., Kerhoas, L., Debeaujon, I., Pourcel, L., Caboche, M., Einhorn, J., and Lepiniec, L. (2006) Flavonoid diversity and biosynthesis in seed of Arabidopsis thaliana. Planta 224:96-107.

Sancho, L.G., de la Torre, R., Horneck, G., Ascaso, C., de Los Rios, A., Pintado, A., Wierzchos, J., and Schuster, M. (2007) Lichens survive in space: results from the 2005 LICHENS experiment. Astrobiology 7:443-454.

Sheahan, J.J. (1996) Sinapate esters provide greater UV-B attenuation than flavonoids in Arabidopsis thaliana (Brassicaceae). American J Bot 83:679-686.

Shklovskii, I.S. and Sagan, C. (1966) Intelligent Life in the Universe, Holden-Day, San Francisco. 
Stapleton, A.E. and Walbot, V. (1994) Flavonoids can protect maize DNA from the induction of ultraviolet radiation damage. Plant Physiol 105:881-889.

Tepfer, D. (2008) The origin of life, panspermia and a proposal to seed the Universe. Plant Science 175:756-760.

Tepfer, D. and Leach, S. (2006) Plant seeds as model vectors for the transfer of life through space. Astrophys Space Sci 306:69-75.

Tepfer, D., Garcia-Gonzales, R., Mansouri, H., Seruga, M., Message, B., Leach, F., and Perica, M.C. (2003) Homologydependent DNA transfer from plants to a soil bacterium under laboratory conditions: implications in evolution and horizontal gene transfer. Transgenic Res 12:425-37.

Urquiaga, I. and Leighton, F. (2000) Plant polyphenol antioxidants and oxidative stress. Biological Research 33:55-64.

Wei, L.J., Yang, Q., Xia, H.M., Furusawa, Y., Guan, S.H., Xin, P., and Sun, Y.Q. (2006) Analysis of cytogenetic damage in rice seeds induced by energetic heavy ions on-ground and after spaceflight. L Radiat Res 47:273-278.

Westall, F. (2009) Life on an anaerobic planet. Science 323:471-472.

Williams, R.J., Spencer, J.P.E., and Rice-Evans, C. (2004) Flavonoids: antioxidants or signalling molecules? Free Radic Biol Med 36:838-849.

Yu, O., Shi, J., Hession, A.O., Maxwell, C.A., McGonigle, B., and Odell, J.T. (2003) Metabolic engineering to increase isoflavone biosynthesis in soybean seed. Phytochemistry 63:753-763.
Zalar, A. (2010) Resistance of Arabidopsis thaliana seeds exposed to monochromatic and simulated solar polychromatic UV radiation: preparation for the EXPOSE space missions to the International Space Station (ISS). Ph.D. thesis, Université de Versailles Saint-Quentin-en-Yvelines, Versailles, France.

Zalar, A., Tepfer, D., Hoffmann, S.V., Kollmann, A., and Leach, S. (2007) Directed exospermia: II. VUV-UV spectroscopy of specialized UV screens, including plant flavonoids, suggests using metabolic engineering to improve survival in space. International Journal of Astrobiology 6:291-301.

Address correspondence to: David Tepfer PESSAC

Institut National de la Recherche Agronomique 78026 Versailles France

E-mail: david.tepfer@gmail.com

Submitted 7 October 2011 Accepted 14 April 2012 
This article has been cited by:

1. Elke Rabbow, Petra Rettberg, Simon Barczyk, Maria Bohmeier, André Parpart, Corinna Panitz, Gerda Horneck , Ralf von Heise-Rotenburg, Tom Hoppenbrouwers, Rainer Willnecker, Pietro Baglioni , René Demets , Jan Dettmann , Guenther Reitz . 2012. EXPOSE-E: An ESA Astrobiology Mission 1.5 Years in Space. Astrobiology 12:5, 374-386. [Abstract] [Full Text HTML] [Full Text PDF] [Full Text PDF with Links] 